\title{
EFFECTIVENESS OF AUTOMATED ENFORCEMENT SYSTEM (AES) IN REDUCING RED LIGHT VIOLATION (RLV) BEHAVIOURS: A CASE STUDY IN KUALA LUMPUR
}

\author{
Kabit, M.R. ${ }^{{ }^{*}}$, Sabihin, N.A. ${ }^{2}$ and Wan Ibrahim, W.H. ${ }^{3}$ \\ ${ }^{1,2,3}$ Faculty of Engineering, Universiti Malaysia Sarawak, 94300 Kota Samarahan, Sarawak \\ Date received: 25/11/16, Date accepted: 20/4/16 \\ Corresponding author's email: kraduan@unimas.my
}

\begin{abstract}
The national statistics indicates that red light violations (RLV) have become a significant safety problem throughout the nation. As a result, the Malaysian government has initiated the installation of automated enforcement system (AES) to reduce RLV related crashes at identified critical locations particularly in Kuala Lumpur region. The primary aim of this study was to evaluate the effectiveness of AES installation in reducing RLR at signalised intersections using a case study at Jalan Ipoh, Kuala Lumpur. Before and after AES installation data were collected and were analysed using a statistical tool. T-test results indicated that the installation of AES has significantly reduced RLV behaviours at the studied signalised intersection. The results of this study provide a useful insight on the benefits of AES in decreasing intersection related crashes by means of reducing RLV behaviours among the road users through AES installation.
\end{abstract}

Keywords: red light violation, signalised intersection, Automated Enforcement System (AES), t-test

\subsection{INTRODUCTION}

$\mathrm{O}$ ne of the major factors that have led to signalized intersection crashes is red light violation (RLV) behaviours. In Malaysia, intersection collisions have resulted in 207 deaths and 706 injuries in 2011 [1]. RLV occurs when the front wheels of a vehicle entered the defining boundary of an intersection (usually the stop line) after the traffic signal had changed to the red phase and the vehicle proceeded through the intersection while the signal was red [2].

According to the National Highway Traffic Safety Administration's (NHTSA) Traffic Safety Facts 2008 Report [3], there were more than 2.3 million reported intersection-related crashes, resulting in more than 7770 fatalities in the US. Of these, 762 were caused by red-light running [4]. In addition, an estimated 165,000 people were injured annually by red-light runners as reported by NHTSA's Fatality Analysis Reporting System. The results obtained from National Survey of Speeding and Other Unsafe Driver Actions [5], revealed that $97 \%$ of drivers feel that other drivers running red-lights are a major safety threat.

As the number of registered vehicles Malaysia is indicating a steady rising trend, it is expected that more vehicles related crashes will occur on Malaysian roads in the future. Thus, to mitigate the rising trend of road crash occurrence in Malaysia, the government has deployed AES installation at 14 black spot locations in Perak, Selangor and Kuala Lumpur in 2012. Three types of AES camera which are mobile camera, fixed speed camera and red light camera have been installed together with an AES warning sign which is visible $2-3 \mathrm{~km}$ before the exact location of AES in operational.

This study aims to measure the effectiveness of AES in reducing the number of RLV at signalised intersection. 


\subsection{LITERATURE REVIEW}

Bonneson and Zimmerman [6] identify the vehicle that runs the red light as: "a vehicle that enters the intersection or passes the stop line after the red light turns on". This means that it is legal for a motorist to pass the stop line when the light is yellow.

Che Puan et al. [7] discovered approximately $13.43 \%$ of the drivers tend to accelerate to clear the intersection at the onset of amber period and about $26.32 \%$ of the drivers ended up with running the red light in Johor Baharu, Malaysia. They also found that the probability of drivers' decision either to stop or proceed at an onset of amber period was influenced by his/her distance from the stop line and his/her position in the platoon.

Generally, the safety of signalised intersections is extensively dependent on drivers' compliance with the traffic control devices. Nevertheless, some road users may intentionally and non-intentionally jump the red lights, and therefore increase their crash risk. Automated Enforcement System (AES) or also known as Red Light Running Cameras (RLCs) have been installed in a many major cities around the world, including Malaysia to reduce RLV and road crashes due to such negative behaviours. The main goal of AES is to change drivers' behaviour on obeying the red light at intersections. Automated red light enforcement cameras have been shown to substantially reduce red light violations by photographing vehicles whose drivers run red lights [8]. The main idea of the automated red light camera is the continuous monitoring of the traffic flow and the traffic signal. The camera will be triggered to capture the vehicle's license plate of any vehicle passing over the sensors beyond the stop line and a specified time after the signal has turned red. Retting et al., [9] reported that RLV is a common traffic violation resulting in an average of 750 fatalities annually and more than 260,000 injuries every year in the US.

In the US, enforcement of red light cameras in both Oxnard, California and Fairfax, Virginia has resulted in a 40 percent reduction in red light violations during the first year of system deployment [10, 11]. The study concluded that that AES program would lead to the general change of drivers' behaviour. Although the study found the positive effect of AES program in decreasing the frequency of left turn and angle crashes, the rear-end crashes however have increased due to non-uniform changes in driver behaviour especially at the beginning period after installation of AES at the studied intersections.

The use of AES in Essex, UK, has resulted in a $88 \%$ decrease in RLV [12], while 32 percent to 50 decreases in right-angle crashes were reported in Melbourne, Sydney, and Victoria in Australia [13, 14].

Erke [15] found that the deployment of AES program has led to a $10 \%$ reduction in right-angle crashes and a $40 \%$ increase in rear-end crashes based on a meta-analysis of the effects of AES on crashes undertaken.

Ahmed and Abdel-Aty [8] discovered that there was a consistent significant reduction in angle and leftturn crashes and a significant increase in rear-end crashes on target approaches upon the installation of AES in in Orange County, Florida which confirmed an earlier findings by Retting et al. [10,11]. The study concluded that the magnitude and the direction of these effects, to a lesser degree, were found similar on the whole intersection.

Fitzsimmons et al. [16] used a cross-sectional analysis the effectiveness of red light running cameras in reducing the number of RLVs in Iowa. A Poisson lognormal regression results indicated that red light running cameras substantially reduced the number of violations at camera-enforced approaches as compared to control approaches. 


\subsection{METHODOLOGY}

\section{Data collection}

A signalised T-intersection at Jalan Ipoh, Kuala Lumpur was chosen as the study site as shown in figure 1. The major road is a two-way divided arterial comprising three lanes in each lane in each direction linking traffic to a freeway at each end. To compare the effectiveness of AES installation, the data were collected for both before and after AES installation at the choosen study location. The data collection was undertaken as follows:

a. Before AES installation- two hours data collection for AM Peak and Peak

b. After AES installation - two hours data collection for AM Peak and Peak

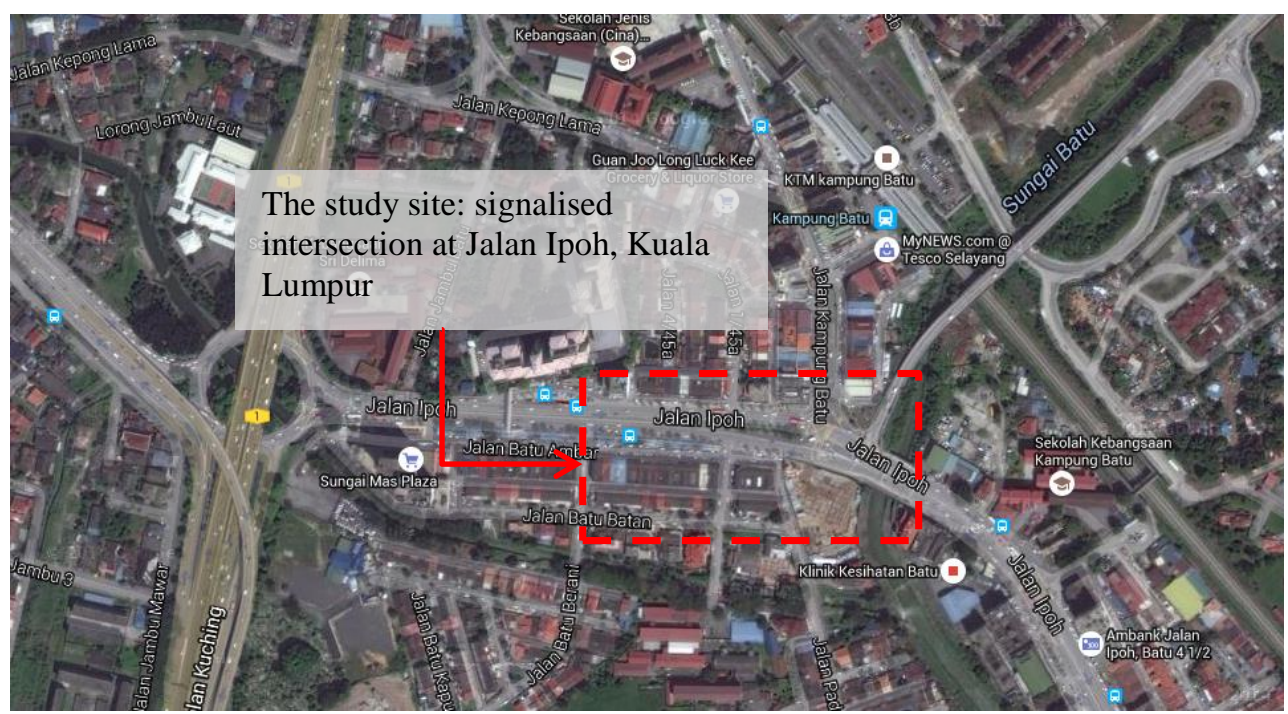

Figure 1: Data collection site (source: google map)

During the data collection process, vehicular volumes were observed and the number of RLV with respect to vehicle type, road type, type of approaches and signal timing were recorded.

Analysis

The reduced traffic data were analysed using Statistical Package for Social Science (SPSS) software. Two sample means t-test was performed. T-test can be computed using the following formula:

$$
t=\frac{\bar{X}_{1}-\bar{X}_{2}}{\sqrt{\frac{s_{1}^{2}}{N_{1}}+\frac{s_{2}^{2}}{N_{2}}}}
$$

Where, $\mathrm{x}_{1}=$ Mean othe firstst set of values, $\mathrm{x}_{2}=$ Mean of second set of values, $\mathrm{S}_{1}=$ Standard deviation othe first set of values, $\mathrm{S}_{2}=$ Standard deviation of second set of values, $\mathrm{n}_{1}=$ Total number of values in first set, $\mathrm{n}_{2}=$ Total number of values ithe second setet.

In this case, we require two separate sample means, standard deviations and sample sizes. The number of degrees of freedom is computed using the formula

$$
D F=\frac{\left(\frac{s_{1}^{2}}{n_{1}}+\frac{s_{2}^{2}}{n_{2}}\right)^{2}}{\left[\frac{1}{n_{1}-1}\left(\frac{s_{1}^{2}}{n_{1}}\right)^{2}+\frac{1}{n_{2}-1}\left(\frac{s_{2}^{2}}{n_{2}}\right)^{2}\right]}
$$




\subsection{RESULTS AND DISCUSSIONS}

\section{Before and after AES installation comparison}

An independent T-test was conducted to compare the number of total violations before and after installing the AES. There was a significant difference in the scores for total violation before $(\mathrm{M}=4.73$, $\mathrm{SD}=7.40)$ and the total violation after $(\mathrm{M}=2.17, \mathrm{SD}=3.77)$ conditions; $t(2)=4.39, p=0.000<0.05$. Therefore, reject $\mathrm{H}_{0}$ at $\alpha=5 \%$ and accept the alternative hypothesis, $\mathrm{H}_{\mathrm{a}}=\mu_{\mathrm{d}}>0$. These results suggest that AES does have a significant effect on RLV reduction when installed at signalised intersection.

The finding from this study is consistent with the findings of past studies by Retting et al. [10,11] and Fitzsimmons et al. [16] which concluded that AES program is effective in reducing RLV behaviours at signalised intersections.

Comparison of vehicle types, turning movements, timing and road type (before and after AES installation)

Table 1 shows the results summary of t-test comparing means between before and after AES installation with a consideration of different type of vehicles, turning movement, and time of a day.

Table 1: T-test results for Pattern of vehicle type, movement, timing and road type for before and after the installation of AES

\begin{tabular}{|c|c|c|c|c|c|}
\hline & $N$ & Mean & Std. Deviation & $F$ & Sig. \\
\hline \multicolumn{6}{|l|}{ vehicle type } \\
\hline motorcycle & $40(40)$ & $3.98(2.25)$ & $4.60(3.40)$ & $14.522(12.86)$ & $0.000(0.000)$ \\
\hline car & $40(40)$ & $9.08(4.08)$ & $10.49(4.88)$ & & \\
\hline vehicle & $40(40)$ & $1.13(0.18)$ & $1.71(0.45)$ & & \\
\hline \multicolumn{6}{|l|}{ Movement } \\
\hline through & $24(24)$ & $6.54(1.71)$ & $5.70(2.01)$ & $4.532(4.70)$ & $0.005(0.004)$ \\
\hline right turn & $48(48)$ & $5.81(2.77)$ & $9.30(4.41)$ & & \\
\hline u turn & $24(24)$ & $5.46(3.58)$ & $6.68(4.66)$ & & \\
\hline \multicolumn{6}{|l|}{ Timing } \\
\hline peak & $60(60)$ & $3.12(2.18)$ & $5.29(4.23)$ & $5.893(0.002)$ & $0.017(0.992)$ \\
\hline $\begin{array}{l}\text { offpeak } \\
\text { road type }\end{array}$ & $60(60)$ & $6.33(2.15)$ & $8.80(3.28)$ & & \\
\hline major & $72(72)$ & $4.53(1.96)$ & $5.57(3.22)$ & $0.127(0.55)$ & $0.722(0.461)$ \\
\hline minor & $48(48)$ & $5.02(2.48)$ & $9.59(4.49)$ & & \\
\hline
\end{tabular}

There was a significant difference in the violation scores for vehicle types in contributing to RLV behaviours before the installation of AES, $\mathrm{t}(2)=14.522, \mathrm{p}=0.000$. Of the observed vehicle types, passenger car $(M=9.08, S D=10.49)$ contributed to the highest RLV score followed by motorcycle $(M$ $=3.98, \mathrm{SD}=4.60)$ and other type of vehicles $(\mathrm{M}=1.13, \mathrm{SD}=1.17)$ before the installation of AES condition. A similar trend was found upon the installation of AES at the studied intersection, which the results indicated that there was a significant a significant difference in the violation scores for vehicle types in contributing to RLV behaviours upon the installation of AES, $t(2)=12.86, p=0.000$.

As for the vehicle turning movements, there was a significant difference in the violation scores for vehicle turning movements in contributing to RLV behaviours upon the installation of AES, t (2) =4.7, $\mathrm{p}=0.004$. Before the installation of AES, through vehicle movement $(\mathrm{M}=6.54, \mathrm{SD}=5.70)$ scored the highest rate of RLV followed by right turn $(\mathrm{M}=5.80, \mathrm{SD}=9.04)$ and u-turn movement $(\mathrm{M}=5.48, \mathrm{SD}=$ 6.68). Upon the installation of AES, there was a significant reduction in RLV behaviours with respect to 
the turning movements, by which u-turn movement scored the highest rate of violations $(\mathrm{M}=3.58, \mathrm{SD}=$ 4.66).

The results also revealed that a significant difference in the RLV for off peak hour $(\mathrm{M}=6.33$, $\mathrm{SD}=8.798)$ and peak hour $(\mathrm{M}=3.12, \mathrm{SD}=5.29)$ before the installation of AES condition; $\mathrm{t}(1)=5.89, \mathrm{p}$ $=0.017$. However, the observed RLV for both peak hours and off peak hour was found to be insignificant different upon the installation of AES $(t(1)=0.002, p=0.962$.

There was no significant difference in the violation scores occurred on the major road and on the minor road when before $(\mathrm{t}(1)=0.127, \mathrm{p}=0.722)$ and after AES installation $(\mathrm{t}(1)=0.548, \mathrm{p}=0.461)$ results were compared as shown in table 1 .

As the results generally indicated a positive effect in reducing RLV behaviours among the different types vehicle users and different turning movements at signalise intersections. Thus, it is believed that a significant road crashes, especially right-angle crashes and rear-end crashes could be reduced as a result of AES installation which is in good agreement with the reported findings in the previous studies [8, 12, $13,14,15]$

\subsection{CONCLUSIONS AND RECOMMENDATION}

In this investigation, the aim was to evaluate the effect of AES installation at signalised intersection, Jalan Ipoh, Kuala Lumpur, Malaysia. The findings suggest that in general AES installation was a significant strategy in reducing RLV behaviours at signalised intersection, which consistent with findings of past studies conducted overseas. With a significant decrease in RLV upon the installation of AES, it is predicted that the safety risk at signalised intersection will be considerably improved in the future.

It is suggested that a further research should be undertaken to examine the effect of signal timing improvement on RLV behaviours with a consideration of AES installation and vehicle speed parameters.

\section{ACKNOWLEDGMENT}

The authors would to thank Crash and Exposure Data Unit (CDE) of Malaysian Institute of Road Safety Research (MIROS) for their support in assisting the researchers during data collection process.

\section{REFERENCES}

[1] Malaysian Institute of Road Safety Research, (MIROS). 2012. Statistical Report on Road Accidents in Malaysia.

[2] Passetti Karl A., 1997. Use of Automated Enforcement for Red Light Violations”. CVEN-677 Advanced Surface Transportation Systems, Department of Civil Engineering, Texas A\&M University, College Station, Texas.

[3] National Highway Traffic Safety Administration, 2008a. Traffic Safety Facts 2008 Report. http://www-nrd.nhtsa.dot.gov/Pubs/811170.PDF

[4] National Highway Traffic Safety Administration, 2008b. HTSA's Fatality Analysis Reporting System (FARS) reports. http://www.fars.nhtsa.dot.gov/Main/index.aspx

[5] National Highway Traffic Safety Administration, 2004. The National Survey of Speeding and Other Unsafe Driver Actions Vol. 2: Findings, Report No. DOT HS 809 730, National Highway Traffic Safety Administration, May 2004. http://www.nhtsa.gov/people/injury/aggressive/unsafe/att-beh/cov$\underline{\text { toc.html }}$

[6] Bonneson, J. and Zimmerman, K., 2004. Red Light Running Handbook: An Engineer's Guide to Reducing Red-light Related Crashes, Texas A \& M University, College Station, Texas

[7] Che Puan, O., Ibrahim, M.N., Muhammad Nor, M.S, and Trian, E., 2014. Driver's Decision Model at an Onset of Amber Period at Signalised Intersections, Journal Teknologi. 72 (5): 35-39.

[8] Ahmed, M.M. and Abdel-Aty, M., 2015. Evaluation and spatial analysis of automated red-light running enforcement cameras, Transportation Research Part C. 5, 130-140.

[9] Retting R.A, Ferguson S.A, \& Hakkert A.S (2003). Effects of Red Light Cameras on Violations and Crashes: A review of the International Literature. Traffic Injury Prevention. 4: 17-23.

[10] Retting, R.A.; Williams, A.F.; Farmer, C.M.; and Feldman, A.F. 1999a. Evaluation of Red Light Camera Enforcement in Oxnard, California. Accident Analysis and Prevention. 31: 169-74 
[11] Retting, R.A.; Williams, A.F.; Farmer, C.M.; and Feldman, A.F., 1999b. Evaluation of Red Light Camera Enforcement in Fairfax, Virginia. ITE Journal. 69: 30-34.

[12] Rocchi, S., Hemsing, S.A., 1999. Review of the Road Safety Benefits of Red Light Cameras. CD-ROM Enhancing Transportation Safety in the 21st Century, ITE. International Conference. Institute of Transportation Engineers, Washington, DC.

[13] Hillier, W., Ronczka, J., Schnerring, F., 1993. An Evaluation of Red Light Cameras in Sydney. Roads and Traffic Authority, New South Wales, Australia.

[14] South, D., Harrison, W., Portans, I., King, M., 1988. Evaluation of the Red Light Camera Program and the Owner Onus Legislation. Victoria Road Traffic Authority, Victoria, Australia.

[15] Erke, A., 2009. Red light for red-light cameras? a meta-analysis of the effects of red-light cameras on crashes. Accid. Anal. Prevent. 41: 897-905.

[16] Fitzsimmons, E. J., Hallmark, S. L., Orellana, M., McDonald, T., and Matulac, D., 2009. Investigation of Violation Reduction at Intersection Approaches with Automated Red Light Running Enforcement Cameras in Clive, Iowa, Using a Cross-Sectional Analysis, Journal of Transportation Engineering, ASCE, 135 (12): 984-989. 